\title{
La renovació pedagògica a la postguerra en Catalunya (1950-1980)
}

\section{The post-war pedagogical renewal in Catalonia (1950-1980)}

Jordi Monés i Pujol-Busquets

\begin{abstract}
RESUMO: Jordi Monés, el máis cregut analista de la historia educativa contemporánea de Catalunya, presenta l'escenario educatiu catalán dels pasados anys sesenta i setanta; un escenario on, malgrat de totes les limitacións introduïdes pel franquisme, es construïa con pezas procedents dels impulsos del movemento de l'Escola Nova i de la propia memoria republicana, el que aviat iría ser la Nova Escola Pública Catalana.
\end{abstract}

PALABRAS CHAVE: Escola franquista, catalanismo cultural, memoria i renovació pedagóxica, Rosa Sentat.

ABSTRACT: Jordi Monés, the most accredited analyst of the contemporary history of education of Catalonia, presents the Catalan educational context of the past sixties and seventies. A context that, although all the limitations introduced by Franco's regime, was built with pieces coming from the impulses of the New School movement and from the republican memory, what soon would become the New Catalan Public School.

KEY WORDS: Francoist school, cultural Catalanism, pedagogical renewal and memory, Rosa Sensat Puntualitzacions preliminars.

Ateses les característiques d'aquest treball, em centraré en l'evolució de la renovació pedagògica a Catalunya i, en segon terme, en la seva interrelació amb experiències similars que començaren a produir-se en altres contrades de la resta de l'Estat. Aquest moviment es va desenvolupar en un marc sociopolític contrari als seus objectius i, conseqüentment, al seu projecte educatiu. Haurem de fer, doncs, una breu referència a allò que va representar el triomf del franquisme ${ }^{1}$.

1. És evident que en molts llocs de l'Estat espanyol el franquisme va començar ja a partir del juliol del 1936, però, en canvi, poc abans de la rendició, hi havia encara moltes contrades sota el control dels republicans. Considerem, doncs, que, en general, el franquisme s'inicia a partir del dia 1 d'abril de 1939, final de la guerra. 


\section{El franquisme fins els anys seixanta.}

\section{Precisions prèvies}

No es pot intentar entendre el franquisme a partir només d'un esquema historiogràfic politicoeconòmic. Menystenir la història cultural i la història de l'educació ens portaria a conclusions qüestionables. D'altra banda cal preguntar-se si existeixen un o diversos franquismes al llarg d'aquest període. Si mirem el problema des de l'òptica de l'estructura i dels mitjans educatius, fa tota la impressió que existeix més d'un franquisme. Si ens fixem, però, en les seves bases ideològiques, observem una certa essència que es manté invariable fins a la mort del dictador.

\section{El primer període. Context polític i educatiu (1936-1939)-1945.}

Aquest període comprèn els anys de l'última Guerra Mundial (1939-1945), època en què el món polític i el marc educatiu espanyol es caracteritzaren sobretot per:

Un control estricte dels mitjans de comunicació públics i privats; una dura repressió política; l'estat totalitari d'acord amb l'eix Roma-Berlín-Tokio, amb totes les seves derivacions, tot i que a partir de 1943 començaren a notar-se alguns canvis (...). Al món politico-pedagògic es produeix un trencament total amb l'anterior model escolar, la qual cosa va comportar: depuració i persecució política dels ensenyants que, en alguns casos, derivaria en condemna a mort; contracte a professors addictes al règim; sindicació obligatòria als sindicats oficials; unitarisme; prohibició de les llengües no castellanes; separació de sexes i masculisme (la universidad es cosa de hombres); subsidiarietat; ajut directe 0 indirecte a l'escola religiosa; ordre i disciplina; actitud passiva de l'alumne; càstigs, fins i tot corporals (...).

L'essència ideològica es concretava en les tres grans unitats: una sola pàtria, l'Espanya castellana, una sola religió, la catòlica, un sol tipus de família, la tradicional espanyola heretada del segle XIX. El magisteri es considerava un art. Tot i la reinstauració de l'escola anterior al 1931, la influència falangista fou important, la qual cosa significava una certa incidència de les escoles nazi i feixista. Malgrat tot, es va acabar imposant la ideologia coneguda com a nacional-catolicisme.

\section{Període 1946-1960. Final de la 2a Guerra mundial $i$ integració a l'economia occidental}

El triomf dels aliats obligà a canvis, com a mínim aparents. Malgrat la retirada d'ambaixadors, les grans potències donaren suport a l'Estat espanyol "bastión mundial del anticomunismo". Durant els primers temps, s'estructurà l'Estat i s'aprovaren les "Leyes del Movimiento". Espanya va esdevenir una "democràcia orgànica", basada en estaments, és a dir les bases de l'Antic Règim, i no pas en grups socials. S'inicià una pèrdua d'influència de la Falange en el marc d'una "aparent" despolitització. 
El 1938, en plena guerra civil, s'havia aprovat a Burgos la Ley de Enseñanza Media i, el 1943, la de Enseñanza Universitaria En aquests anys es completà l'estructura educativa legal amb l'aprovació, el 1945, de la Ley de Enseñanza Primaria. En els tres casos, les decisions es prenien sempre de dalt a baix. El 1951 l'Estat espanyol ingressava a la UNESCO.

L'escola era obligatòria dels 6 als 12 anys i només gratuïta per als pobres. No s'observen massa canvis en la realitat escolar. El franquisme escolar va aconseguir un cert suport popular. Entre 1948 i 1955 va néixer la nova formació professional. L'entrada de Joaquin Ruiz Jiménez al ministeri d'Educació, el 1951, ens va situar en un altre context on se superà, almenys en part, el maniqueisme, tot i que continuaren les diferències entre espanyols bons i dolents.

La difícil situació de les classes subalternes, la repressió política i l'ínfim nivell de vida generarenuna sèrie de protestes com la vaga general a Manresa, el 1946, la vaga general al País Basc, el 1947; la vaga a Barcelona de pujar al tramvia l'1-III-1951, seguida de vagues a diverses fàbriques de Catalunya (...).

Al cap d'un cert temps, es produí una certa acceptació del sistema gràcies als canvis en la política econòmica: superació de l'autarquia, acords, el 1953, amb el Estats Units, el Pla d'Estabilització el 1959, inici de la incorporació econòmica a Europa. En el món educatiu, el 1953, la nova llei de l'Ensenyament Mitjà, Ilei de Construccions Escolars, (...)..

\section{La renovació pedagògica}

\section{Els precedents.}

La resistència al nou ordre escolar es manifestà des del primer moment, especialment en els llocs on la República havia deixat una major empremta. Malgrat les seves limitacions, les experiències d'aquells anys, van tenir un valor significatiu i constituïren un preludi del que succeirà més endavant ${ }^{2}$. A partir, més o menys de 1950, es produïren alguns intents de renovació de l'escola, a causa, en part, del menor control ideològic sobre alguns sectors de la iniciativa privada.

El nou moviment escolar es manifestà a Catalunya, des de 1939, primer individualment però amb vincles personals i de grup, la qual cosa determinà, temps a venir, que una sèrie de mestres i mestresses, preocupats per la situació de l'educació a Catalunya, intentessin portar a terme una sèrie d'accions conjuntes.

Quan parlem de renovació pedagògica ens referim a un projecte educatiu que va més enllà d'una proposta de caràcter individual. Malgrat les limitacions amb què es plantejava en ple franquisme, va tenir un sentit de projecte col-lectiu. Les experiències dels anys

2 Hi ha una certa informació al respecte, fins i tot biografies àmplies d'algunes escoles d'aquelles èpoques. Vegeu: Marta Mata (2001) "Un període difícil " pàg., 29-82: Jordi Monés Pujol-Busquets (2011), pàg., 315-326. 
cinquanta-seixanta es poden considerar com una continuació de la renovació pedagògica del període 1900-19393.

\section{La renovació pedagògica pròpiament dita (1950-1980).}

\section{Els primers moviments a Catalunya}

L'augment de la demanda escolar propicià l'establiment de noves escoles per eixugar, en part, el dèficit escolar que s'anava produint. Molts mestres, no pas la majoria, començaren a interessar-se per un nou tipus d'escola. D'aquí va sorgir l'interès per l'intercanvi. Hom mirava d'influir en una part del cos ensenyant, especialment a l'escola elemental i primària.

Entre els anys cinquanta-seixanta, nasqueren una sèrie de projectes per tal d'incidir en la projecció social i ciutadana de l'activisme escolar 4 , amb la particularitat, però, que els coneixements teòrics dels mestres sobre l'escola activa eren força limitats. Per solucionar aquest dèficit, Alexandre Galí organitzà uns cursos de Pedagogia a casa seva entre 1958 i 1963, a partir de les vuit del vespre. Es tractava d'oferir eines als mestres per tal que comprenguessin allò que representava l'escola activa i allò que havia significat a Catalunya abans de la Guerra Civil. Aquest cursos donaren una certa cohesió als docents d'una sèrie d'escoles que s'havien anat creant ${ }^{5}$

D'altra banda, una grup de mestres procedents d'ACO (Acció Catòlica Obrera) i de l'escola Thalita ${ }^{6}$ es reunien mensualment ${ }^{7}$. A l'estiu es trobaven a la casa pairal de la Marta Mata a Saifores, on feien l'anàlisi de les reunions del curs. Aquests encontres varen tenir lloc els anys 1961 i 1962 i foren batejats amb el nom de Congressos de Pedagogia barata. Hom discutia temes pedagògics de caràcter general. El debat se centrava, sobretot, en la problemàtica de la responsabilitat social del mestre.

Parallelament es formava el grup de Pax Christi, sota l'empar legal dels Amics de la UNESCO, que partia de la Declaració de l'ONU sobre els drets dels infants. Aquest grup va organitzar els anys 1960, 1961 i 1962 una sèrie d'activitats per aglutinar persones

\footnotetext{
3 Sobre la recuperació pedagògica de la postguerra, vegeu: Jordi Galí .(1978), pàg., 27-28.

4 AlexaAlexandre Galí i Artur Martorell grans pedagogs del període 1900-1939, van ser determinants en la represa dels anys cinquanta-seixanta

5 Entre aquestes escoles citarem: 1950, Carles Capdevila, l'escola de la Molina on hi trobarem, a més, Maria Teresa Codina i mossèn Bosch fundador de l'escola Décroly; 1953, l'escola Laietana, Josep Pereña i els germans Jarque ; 1955, l'escola Sant Gregori, Jordi Galí que havia assistit a l'Escola de la Molina.. Una atenció especial mereixen la creació de l'Escola Thalita, la seva impulsora M..T. Codina, l'octubre del 1956 i el 1957 de l'escola Costa i Llobera, per part de Pau López, Pere Darder i Enric Lluch.

6 .Sobre aquesta escola i sobre la línia pedagògica dels primers temps 1956-1959), consulteu: Maria Teresa Codina, (2007), pàg., 33-108.

7 En aquest grup, a més de la gent d'ACO i de Thalita, hi havia la Pepita Casanelles que treballava a l'escola parroquial de Can Tunis, Nostra Sra. del Port, zona molt deprimida- mestres de Mataró, del barri de Cerdanyola de Vilanova, Roser Bataller - de l'Hospitalet de Llobregat - ( . . .).
} 
interessades a conèixer la realitat escolar ${ }^{8}$. Aquestes reunions eren conegudes com a convivències, la qual cosa denota el caràcter eclesial del grup 9 .

De la fusió d'alguns elements dels dos grups abans esmentats van néixer les Sessions de Pedagogia, iniciades el 28 de juny de 1963, molts elements de les quals s'integrarien més tard a "Rosa Sensat". A les sessions hi participaren pedagogs que esdevingueren figures destacades del món educatiu català. Provenien, en general, de les escoles Talitha, Costa Llobera i Thau ${ }^{10}$.

A més de la catalanització de l'escola en llengua i continguts ${ }^{11}$, a nivell acadèmic la primera preocupació d'aquests pedagogs va ser recuperar la tradició anterior al 1939. Recordem que, més o menys, el 1955 es va re introduir el mètode Montessori en alguns col.legis, de monges entre altres ${ }^{12}$. A Catalunya, però, hom intentà superar un cert immobilisme dels seguidors oficials del mètode ${ }^{13}$.

A principis dels anys seixanta es va crear l'Escola de Jardineres del $\mathrm{CICF}^{14}$, (Centre d'Informació Catòlica Femenina), on el mètode Montessori hi jugava un paper important, juntament amb el mètode Decroly. Pel que fa a aquest mètode, no podem parlar de recuperació fins el 1960, quan Mossèn Bosc va crear l'escola Decroly a la ciutat de Barcelona. ${ }^{15}$

A part de Montessori i Decroly, de la tradició anterior no podem oblidar Jean Piaget $i$ Célestin Freinet, que havien donat conferències a Barcelona els anys 1930 i 1933 respectivament. A la dècada dels seixanta, Genoveva Sastre i Montserrat Moreno, llicenciades

8 Aquesta gent que es reunia els estius al Pirineu, treballaven una sèrie de qüestions socioeducatives. Recordarem l'elaboració d'un fitxer dels mestres en actiu a Catalunya.

9 En línies generals, tots els grups que conduïren a la fundació de "Rosa Sensat" eren molt religiosos, a la línia del que seria el Vaticà II. Consulteu; M. Teresa Codina (2007), pàg., 66-70 i 99.

10 Thau va ser fundada el 1963, per la Institució Cultural del CIC (Centre d'Informació Catòlica). L'Escola de Jardineres del CICF, a la qual ens referim més endavant, era una Secció Femenina de la mateixa Institució

11 Als primers temps la màxima preocupació se centrava en la idea de llengua materna. Arran de la immigració prendrà protagonisme el concepte llengua social, fet que comportà una divisió entre el grup de "Rosa Sensat" i d'Òmnium Cultural associació capdavantera en la política de llengua escolar, més inclinada a favor del concepte llengua social.

$12 \mathrm{~A}$ ben segur que abans d'aquests anys, hi va haver alguna experiència d'aquest tipus. Ens manquen monografies que ens ofereixin dades concretes.

13. Arran de la creació de l'escola Thalita es produeix una discussió en la qual M.A. Canals es mostrava partidària d'aplicar el mètode Montessosri amb criteri i no com a norma estricta, reflexió que va tenir un gran ressò. Vegeu. Alsina i Soler (coord..) pàg., 35, Codina, 2007, pàg., 80-81. Malgrat tot, es van establir relacions, amb el grup de Madrid, considerat oficial. Professionals de "Rosa Sensat" van assistir a la capital espanyola a un curs Montessori el 23 i 24 de juny de 1972 organitzat per l'INCIE (Instituto Nacional de Ciencias de la Educación). D'altra banda, la nord-americana Judi Amich vinculada al grup Montessori madrileny, va donar una conferència a l'Escola d'Estiu de 1977.

14 Els estudis d'aquest Centre tenien una certa validesa legal, emparant-se en el fet que no hi havia cap escola oficial sobre els jardins d'infants.

15 Sobre aquesta Escola, vegeu, Bosch (1963 i 1964), Bosch i Musset, (1980). 
en Pedagogia per la universitat de Barcelona ${ }^{16}$, es matricularen a la Sorbonne per ampliar estudis amb el psicòleg suís Jean Piaget, professor a París entre 1952 i 1963.

Ja de tornada a Barcelona,, Sastre i Moreno es van fer càrrec de l'assignatura de Psicologia de la Intelligència, a la Secció de Psicologia de la Universitat de Barcelona, que s'havia establert el 1968. Aquestes mateixes professores van jugar un paper decisiu en l'extensió de les idees piagetianes, especialment la Pedagogia Operatòria. En l'extensió d'aquesta disciplina hi ha jugat un paper fonamental I'Institut Municipal barceloní IMIPAE ( Institut Municipal d'Investigació Aplicada a l'Educació) ${ }^{17}$.

La recuperació del moviment Freinet es va produir al País Valencià, amb en Ferran Zurriaga com a capdavanter. Poc després de la mort de Freinet, a les Escoles d'Estiu de 1967 i 1968, mestres del País Valencià i de la Catalunya Nord van impartir cursos sobre aquest mètode i la trajectòria personal de l'educador francès, la qual cosa va propiciar l'extensió del mètode dins de moviment renovador català ${ }^{18}$. En aquesta extensió hi jugà un paper cabdal l'edició dels seus textos més importants i de les seves fitxes en català i castellà, a càrrec de l'Editorial Laia ${ }^{19}$.

La importància que va adquirir el MCEP (Moviment Cooperatiu d'Escola Popular) feu possible la seva extensió, que va adquirir una gran rellevància arreu de l'Estat espanyol ${ }^{20}$. Cal destacar, l'establiment, el 1983, de Nova Escola Galega, vinculada a l'ideari de Freinet.

En la represa del moviment, convé no oblidar Josep Alcobé Biosca, qui, després del seu retorn de l'exili i la consegüent reincorporació al magisteri, va exercir de pont entre els mestres de les velles i joves generacions interessades pel projecte frenetià ${ }^{21}$.

\section{El naixement de "Rosa Sensat".}

En un nou context sociocultural ${ }^{22}$, va néixer aquesta Institució, fruit, principalment, de la confluència de dos factors. Per una banda, els contactes que tingueren els mestres de

16 La Secció de Pedagogia es va establir a Barcelona el 1953. Hi ha molt mal record dels primers temps, però a mesura que passaven els anys, es va anar posant a l'alçada.

17 La universitat de Barcelona a proposta del Departament d Pedagogia, va concedir el títol de doctor Honoris Causa a Jean Piaget. que es féu efectiu el 12 de novembre de 1971. A la recepció, el psicòleg suís va recordar la seva primera visita a Catalunya, el 1925, i l'afecte que sempre havia tingut pel nostre país.

18 Sobre les primeres activitats relacionades amb els inicis del mètode Freinet, al País Valencià i a la Catalunya Nord, podeu consultar: Jordi Monés i Pujol-Busquets, 2011, pàg., 346 notes 65 i 66.

19 A través d'aquests textos es donà a conèixer el mètode cooperatiu, una de les seves essències, el text i les seves fases, la revista escolar, les intervencions dels alumnes, la biblioteca de treball adequada al treball que es fa a classe (...).

20 No incidim en aquesta extensió arreu de l'Estat, ja que compta amb una valuosa i extensa bibliografia.

21 Alcobé treballà en l'extensió del mètode arreu d'Europa i ocupa càrrecs importants dins del moviment a nivell estatal i internacional, com és ara la presidència del MCEP i de la FIMEM ( Federació Internacional del Moviment d'Escola Moderna).

22 En aquesta època, apareix un nou model editorial encapçalat per Edicions 62, la revista Serra d'Or, la Nova Cançó, Comissions Obreres (...). 
moltes de les escoles esmentades per tal de crear una nova Escola i la forma d'enfocar-la i per l'altra el paper que hi varen jugar una sèrie de promotors, com veurem a continuació.

Les primeres reunions convocades pel Dr. Aragó23. i el polític Jordi Pujol van tenir lloc a finals de 1964, amb l'assistència d'una dotzena de persones, a més dels indicats: Damià Casanovas, Joan Triadú, M. Antònia Canals, Joaquim Ramis, Antoni Matabosc, Ricard Foraster(. . .). En aquestes reunions hi havia dues tendències: la de Dr. Aragó, partidari d'una acció a favor de la sanitat i la de Ricard Foraster, favorable a canalitzar els recursos cap al món escolar. L'actitud de Jordi Pujol inclinà la balança a favor de la proposta de Ricard Foraster.

Tot i que la fundació del Dr. Aragó no acabà de reeixir per diversos motius, sobretot legals, M. Antònia Canals, ex-mestra de l'escola Thalita i amiga de Foraste ${ }^{24}$, va convocar una nova reunió a la qual hi assistiren Marta Mata i Antoni Matabosc. Marta Mata no es va comprometre perquè volia comptar amb en Jordi Cots. Superades les primeres dificultats es va convocar una nova reunió amb els ja esmentats i mestres de Talitha i Costa i Llobera $^{25}$.

El nom de "Rosa Sensat" fou proposat per l'Alexandre Galí, en memòria d'aquesta gran pedagoga ${ }^{26}$. Els que podem considerar fundadors/es foren: Marta Mata (1926-2006 )$^{27}$ llicenciada en pedagogia, M. Teresa Codina ( $1927-\ldots$ ) estudià clàssiques i més endavant pedagogia, M. Antònia Canals, (1930- ...) mestra i llicenciada en exactes, Anna M. Roig, (1930- ...) mestra ${ }^{28}$, Pere Darder (1933- ...) llicenciat en Filosofia i Lletres, Enric Lluch, (1928- ) llicenciat en Filosofia i Lletres, secció d'Història, en realitat geògraf ${ }^{29}$ i en Jordi Cots $(1927-\ldots)$ advocat i mestre ${ }^{30}$. Malgrat la titulació de cadascú , allò que els portà a la creació de "Rosa Sensat" no té res a veure amb el que van aprendre a les institucions oficials ${ }^{31}$.

23 El Dr. Aragó volia crear Fiduciària Barcino, seguint l'exemple de Manuel Ainaud a la Comissió de Cultura de l'Ajuntament de Barcelona, a la segona dècada del segle XX, el qual va desenterrar una sèrie de llegats que s'havien deixat perdre.

24 M. Antònia Canals havia fundat l'escola Ton i Guida, (1962-1979) amb l'ajut econòmic de Ricard Foraster. Era la primera escola, vinculada al moviment de renovació pedagògica , situada una barriada obrera - (barri de Verdum)-

25 Talitha era una escola de noies i Costa Llobera de nois. La coeducació, en aquest grup d'escoles, no es generalitzà fins els anys seixanta.

26 Si voleu conèixer la seva vida i la seva trajectòria, vegeu; Josep Gonzàlez-Agàpito, (1989).

$27 \mathrm{Hi}$ ha força bibliografia sobre la vida i la trajectòria de la Marta Mata, a tall d'exemple podeu veure; Raimon Portell (2007). Val la pena no oblidar que entre les moltes distincions que va rebre, s'hi compta el doctorat honoris causa el 1999. Vegeu bibliografia..

28 Aquestes primeres quatre mestres, directament o indirectament, havien tingut relació amb la renovació pedagògica d'abans de la guerra.

29 Pere Darder i Ernest Lluch eren deixebles del Sr Bofill vinculat a la revista Cristiandad.

30 L'advocat Jordi Cots excel.lí com a poeta en català i després estudià magisteri. Fou secretari de les Sessions de Pedagogia juntament amb Fèlix Martí i Joaquim Farré.

31 Els fundadors de "Rosa Sensat", ens han ofert una visió més aviat personal, però imprescindible per conèixer la Institució. Vegeu: M. Antònia Canals, et/al.(2001). 


\section{Les activitats de "Rosa Sensat".}

A la primavera de 1965 es va decidir la creació d'una Escola de Mestres ${ }^{32}$. Marta Mata es responsabilitzà de la seva materialització, juntament amb M. Antònia Canals i Jordi Cots. Prepararen la presentació de la nova Escola de Mestres i de les seves primeres activitats ${ }^{33}$.

L'acte protocol.lari d'inauguració va tenir lloc el 29 de setembre, festa de Sant Miquel, als locals de Franciscàlia. De l'acte destacaríem l'al.lusió que va fer el veterà Pau Romeva a l'Associació Protectora de l'Ensenyança Catalana i la proposta d'Enric Lluch de recuperar les Escoles d'Estiu. Uns dies després, el 4 d'octubre, diada de Sant Francesc d'Assis, la nova Institució iniciava les seves activitat en el marc del que serien els Cursos de Tarda, amb una conferència d'Angeleta Ferrer i Sensat, filla de Rosa Sensat, sobre "La Didàctica de les Ciències Naturals".

El projecte, no massa definit en els primers temps, calia portar-lo a terme a partir de dues activitats específiques: la primera, els cursos organitzats per la Institució: cursos d'hivern, seminaris i grups de treball i, sobretot, les Escoles d'estiu, que foren restablertes el 1966, seguint el model de les escoles de la Mancomunitat (1914-1923) i la de la Generalitat republicana (1930-1935).

Un dels fets més sobresortints de "Rosa Sensat" ha estat la seva evolució, que ha seguit, a grans línies, l'evolució del país:

Estudiarem el període 1965-1980, atès que, a partir d'aquest any, s'obre una etapa totalment diferent. A l'hora de les reflexions finals, ja ens en farem ressò.

Pel que fa al període que estudiem, la seva primera etapa va del 1965-1968, es va intentar crear una estructura i cercar el suport del món sociocultural. Quant a l'estructura, la base humana se centrava en els mestres d'un nucli d'escoles que s'havien creat per tot Catalunya i que portaran a la creació de "Coordinació Escolar", el $1967^{34}$.

En una segona etapa, època de transició, 1968-1970, es començaren a manifestar tensions que no sortiren a la llum fins els anys setanta. Alguns/es mestres criticaven el caràcter "petit burgès" de la Institució i les fórmules de gestió de les escoles de Coordinació Escolar.

El Libro Blanco (1969) i la Llei General d'Educació de 1970 obligaren a replantejar l'estratègia i els objectius de la Institució i de l'oposició en el seu conjunt. En aquest nou

32 Aquesta Institució, tenint en compte el context politicoeducatiu, només podia tenir el caràcter de substitutòria dels centres de formació oficial.

33 Sobre aquesta qüestió, vegeu: Jordi Monés i Pujol-Busquets, 1981, pàg., 21.

34 Al seu naixement Coordinació Escolar estava formada per unes 50 escoles. Vegeu: Jordi Monés i PujolBusquets, 1981, annex ním.5, pàg., 292. Van tenir un paper cabdal en els primers anys de "Rosa Sensat" i van integrar-se, en bona part, a la xarxa pública a la dècada dels vuitanta. Sobre els plantejaments i objectius generals del moviment en aquest període, vegeu: Pere Darder: (2001)." Plantejaments generals" pàg., 83-108: M. Teresa Codina (2002), p. 91-104. 
context es va iniciar una tercera etapa, 1971-1973, durant la qual els plantejaments politicoeducatius passaren davant del pedagogisme. Altrament es produeix una modernització de l'estructura interna, aspectes que es consolidaren durant els anys 1974-1976 ${ }^{35}$.

Arran de la mort del dictador i la convocatòria de les primeres "eleccions democràtiques", es va obrir l'última etapa, 1977-1980, de la Institució en el període que estudiem. A partir de 1980 es produeix una integració al nou ordre polític. Amb la nova situació es renovà l'estructura i la Institució perdé protagonisme'. Naixia "I'Associació de Mestres Rosa Sensat".

Les Escoles d'Estiu han estat un termòmetre de la trajectòria de "Rosa Sensat", que, en el fons, eren el fruit del que la Institució treballava des de l'angle pedagògic i administratiu al llarg del curs. Mostrarem dues vessants de l'esmentada trajectòria. En primer $\| \mathrm{oc}$, tot allò relacionat amb l'escola i la cultura del nostre país i de la resta de l'Estat i, a continuació, la relació amb persones o col.lectius de més enllà de les nostres fronteres.

L'objectiu prioritari era iniciar un camí cap a la normalitat i vers el coneixement de la realitat política i social del país i de l'Estat. Foren diversos els cursos, conferències i seminaris que es realitzaren. Citarem a tall d'exemple:

La incorporació de noves disciplines a l'Escola d'Estiu de 1967, sobretot els cursos de Cançó Popular, les classes de llengua catalana, la Gramàtica estructural i la Matemàtica Moderna a càrrec respectivament de Xesco Boix, Joan Solà, Gabriel Ferrater i Maria Rubies. Les xerrades de Pilar Benejam sobre la "Didàctica de la Geografia"36, d'Eduard Bonet a l'Escola d'Estiu del 1970 sobre "Bertrand Rusell i la teoria de conjunts" i la de José Luís Aranguren sobre "La educación del futuro" a les Escoles d'estiu del 1970 i 1972. El curs sobre Espanya, el 1973, que dictaren diversos especialistes i els cursos de 1973 i 1978 sobre Sociolingüística, a càrrec de Lluís V. Aracil. El curs sobre "La crisi econòmica" amb la participació d'Ernest Lluch, Narcís Serra i Eugeni Giralt, a l'Escola d'Estiu de 1975. Finalment a l'Escola d'Estiu del 1980 el cicle "Catalunya, identitat i futur especialment la Taula Rodona "El futur de la ciència a Catalunya, a càrrec de Joan Oró, Gabriel Ferrater i Enric Casassas. Convé no oblidar que a l'Escola d'Estiu del 1978 hi va intervenir el Seminari d'Història de l'Ensenyament ${ }^{37}$.

Un fet remarcable va ser l'interès de la Institució per expandir-se i per establir el màxim de contactes possibles. Per exemple, la influència que exercí directament o indirecta en la politització, especialment en el període 1973-1977; el paper que jugà en el món cultural, com ho mostren els homenatges a Garcia Lorca i Miguel Hernández; l'homenatge al poeta

35 El fet més destacable és la politització que es manifesta arreu, d'una manera especial, però, a les Escoles d'Estiu, considerades com una mena d'oasi polític.. En aquest període. a les Escoles de 1975 i del 1976 es van fer les propostes sobre una Nova Escola Pública Catalana.

36 Pilar Benejam apuntava que no es pot explicar Didàctica de la Geografia sense uns coneixements mínims de la matèria, reflexió molt adient en aquell moment.

37 Aquest col.lectiu naixia el 1973 i es convertirà en Societat d'Història de l'Educació dels PP. de Llengua Catalana el 1983, avui filial del l'IEC, societat pionera a l'Estat. Prèviament des de 1970, "Rosa Sensat" havia organitzat cursos i seminaris d'Història de l'Educació, activitat poc freqüent fora de Catalunya. 
Vicent Andrés Estellés; la presentació del llibre "La enseñanza en la Segunda República Española" de Mariano Pérez Galán. Els contactes que s'establiren amb els sindicats clandestins de mestres, amb el Col-legi de Doctors i Llicenciats, els ICE, les Comisiones de Maestros y Licenciados (...).

Farem una ullada, també, a un dels aspectes més rellevants de la trajectòria de "Rosa Sensat": els contactes amb altres grups de mestres. A més de la relació amb el País València i Perpinyà, hem de parlar de la visita, el setembre de 1966 al País Basc, d'una Delegació de "Rosa Sensat" per conèixer el moviment de la $/ k a s t o l a^{38}$, el qual a partir d'aquell moment formà part d'un grup que es va ampliar, al cap de poc, amb mestres gallecs. D'aquest tipus de relació nasqué la descentralització de l'Escola d'Estiu. La primera que va tenir lloc fora de Barcelona es va celebrar a Palma de Mallorca, el $1968{ }^{39}$

Aquesta preocupació per tenir contactes amb altres col.lectius de mestres, va generar que, el curs 1971-1972, es creés una Comissió de Relacions Exteriors. A més d'estrènyer llaços amb els grups suara esmentats, especialment a partir de les Escoles d'Estiu de 1973 y 1974, va tenir lloc una trobada amb col.lectius de la resta de l'Estat, sobretot andalusos i madrilenys, que acabarien establint la seva pròpia "Escuela de Verano". En aquest sentit, val la pena recordar que d'ençà de l'Escola del 1969, es programaren cursos en castellà, perquè començaven a matricular-se mestres de les terres de parla no-catalana.

En general, hom havia viscut al marge del que passava més enllà de les nostres fronteres. Però a finals dels anys seixanta les coses van iniciar un canvi, més o menys profund. Algunes de les noves propostes serien recollides en el marc del que podem considerar "moviment pedagògic renovador", independent o vinculat a "Rosa Sensat". Aquests Institució, per mitjà, sobretot de l'Escola d'Estiu, ens va oferir pautes per conèixer les influències que es rebien de fóra del país.

Cal parlar de la influència italiana que presentava diverses vessants, pràcticament sempre vinculades a la problemàtica social. Cal no oblidar la incidència del marxisme teòric $\mathrm{c}^{40} \mathrm{i}$ tenir en compte, sobretot, la relació de "Rosa Sensat" amb el Movimento di Cooperazione Educativa ${ }^{41}$. Val la pena recordar també, i de manera especial, l'interès per l'obra de Lorenzo Milani. ${ }^{42}$, i les lliçons, el 1977, de Gianni Rodari sobre I bambini e i loro libri". ${ }^{43}$

38 El moviment basc ikastola nascut, el 1957, es proposava fonamentalment una recuperació de l'euskera, el qual havia estat perseguit, menystingut i menysvalorat a partir del triomf del franquisme. Aquest moviment se situà més endavant en un context on la pedagogia resultava més determinant.

39 Seguiren les Escoles d'Estiu de Manresa, Granollers, Vic, Lleida, Granollers, Reus, Girona (...). Arran de diferències conceptuals, l'Escola d'Estiu de València no va es va celebrar fins el 1976.

40 La màxima influència la van exercir la traducció de les obres de Gramsci, així com també de Mario Manacorda. 41 Aquest moviment estava totalment integrat a la Pedagogia Popular de Freinet des de 1951 Els intercanvis amb "Rosa Sensat" han estat freqüents. Membres d'aquest grup van assistir a les Escoles d'Estiu de 1974, 1975 i 1976.

42 Vegeu: Alumnes de l'escola de Barbiana, 1998

43 La relació del moviment renovador amb Gianni Rodari s'ha mantingut fins als nostres dies 
Quant a la influència francesa, d'antuvi cal pensar en el maig francès que representà una mena de modernitat que tingué, però, una incidència contradictòria ${ }^{44}$. El 1972, Baudelot i Establet, van donar una sèrie de conferències, entre elles a l'Escola d'estiu 45 . A la del 1976, Louis Althusser impartí una lliçó sobre "Problemes de l'esquerra europea". En aquesta mateixa Escola cal remarcar la presència de l'especialista de la primera infància, Irène Lezine ${ }^{46}$, que havia tingut una relació estreta amb el departament de Psicologia de la Universitat de Barcelona. Convé remarcar la dissertació de Mr. Legrand, del CNRS, sobre "L'Escola Nova i les seves ambigüitats". La conferència de Pierre Vilar a l'Escola d'Estiu de 1978 sobre "Història i Pedagogia, i la xerrada de Jaume Lorés sobre Jean Paul Sartre, que havia mort aquell any.

Finalment convé no oblidar la incidència de l'Amèrica llatina. Esmentarem, en primer lloc, la presència de Helder Camara, arquebisbe de Recife a l'Escola d'Estiu del 1968. Els xilens Pablo Berchenko i Adriana Castillo, estudiosos de Pablo Neruda, a l'Escola d'Estiu de 1977. El moment àlgid de l'interès i la presència de l'Amèrica Llatina es produeix a l'Escola d'Estiu del $1978^{47}$. El fet més significatiu, però, tot i que al marge de "Rosa Sensat", va ser la presència a Barcelona de Paolo Freire i Ivan Illich ${ }^{48}$, i la influència, sobretot de Paolo Freire a qui la Universitat de Barcelona li atorgà el títol de doctor honoris causa ${ }^{49}$. Convé recordar, també, la conferencia que va pronunciar a l'Escola d'Estiu de 1978, Ramon Costa Jou, sobre "Els corrents pedagògics a l'Amèrica Llatina". Exiliat de la Guerra Civil, ha estat un gran propagador del mètode Freinet a Catalunya i a l'Amèrica Llatina.

Ha quedat prou reflectit l'interès d'alguns sectors significatius del moviment en relació al marxisme ${ }^{50}$. Dins de les coordenades de l'època es va observar una forta tendència a favor de la igualtat de gènere, la qual cosa comportà una preocupació per l'educació sexual.

Tampoc hem d'oblidar, de forma minoritària però, un interès pel freudomarxisme ${ }^{51}$. Tot això, més o menys, vinculat a les primeres reivindicacions del moviment feminista ${ }^{52}$. Tot $\mathrm{i}$

44 En aquells anys es produeix a "Rosa Sensat" en particular, i al moviment de mestres en general, l'eclosió del marxisme. En canvi, el maig francès, fou una de les primeres crítiques al marxisme, com a mínim oficial, des de sectors progressistes.

45 Les seves xerrades es van moure entorn del seu libre L'École capitaliste en France que s'acabava de publicar i que produí un gran impacte al moviment renovador, especialment al Departament de Sociologia de Rosa Sensat. 46 En relació a la problemàtica de l'escola Bressol, recordarem que la Secció de Parvulari de "Rosa Sensat" visità en la dècada dels setanta la Unió Soviètica, Moscou, Leningrad i Kiev, França, Marsella i París, Itàlia, Bergamo i Venècia i Hongria, Budapest.

47 Consulteu Jordi Monés i Pujol-Busquets, 1981, pàg., 71.

48 Sobre aquesta visita, vegeu: Alberto Silva/et al.(1975) ",Cuadernos de Pedagogía, pàg., 2-32, Específicament sobre l'educador brasiler, pàg., 23-29- Consulteu, també; Cuadernos de Pedagogía, (1977), (1978).

49 Aquesta distinció li fou concedida l'any 1988. El seu discurs de recepció fou publicat a Paolo Freire (1989), pàg., 300-301.

50 Dins de la suggestió pel marxisme, no podem oblidar l'interès que s'observa per l'obra pedagògica del polonès Suchodolsky, a partir dels anys setanta. Recordem: Bogdan Suchodolsky, (1974).

51 En el món educatiu, l'hem de situar sobretot entre 1970 i 1977 , centrat especialment en l'obra :Wilhem Reich (1970), especialment, Segona part. pàg., 175-295.

52 A partir dels anys seixanta, apareixen diverses feministes, però pel que fa a l'arrencada del moviment organitzat, les historiadores el situen en el període 1973-1982. 
que l'Estat espanyol en va viure al marge, val la pena recordar que, al 1945, s'obrien noves possibilitats educatives enmig de l'impacte i la devastació que s'havia produït a mig món arran de la segona Guerra mundial. Davant d'aquest panorama les preocupacions quantitatives resultaven peremptòries. No és estrany doncs que, a finals dels seixanta, apareguin persones i/o grups que qüestionessin la pràctica educativa allunyada de les descobertes de la Ciències de l'Educació.

El malaurat Joaquim Franch (1944-1987) representa, entre nosaltres, millor que ningú, la vinculació a les noves tendències que van irrompre en el moviment renovador dels anys setanta i principis dels vuitanta. Franch basava les seves propostes i realitzacions encaminades vers l'autogestió escolar en les següents experiències: el programa de l'École Moderne de Freinet de 1945; l'orientació no directiva de Carl Rogers; les pedagogies institucionals de Ferdinand Oury i Aida Vázquez i la de Michel Lobrot i Georges Lapassade ${ }^{53}$; la desescolarització d'Ivan Illich, També va incorporar l'experiència antiautoritària italiana: les propostes de Mac Luhan i les experiències de Makarenko ${ }^{54}$

\section{Altres col.lectius renovadors i la seva relació amb "Rosa Sensat".}

Ja hem vist que el moviment renovador no quedava circumscrit, ni molt menys, a ".Rosa Sensat", tot i que en l'època que estudiem la seva incidència directa o indirecta la trobem arreu. En aquella època, a més de les institucions existents, se'n crearen de noves. Ens interessa, en primer lloc, la Universitat Autònoma de Barcelona i una sèrie de col.lectius que començaven a trencar amb el centralisme barceloní, els quals se sumaren al projecte de reforma iniciat per "Rosa Sensat"55.

Menció especial mereix l'Escola de Mestres de Sant Cugat que s'incorporà més endavant a l'Autònoma i prendrà el nom d'Escola de Formació de Mestres de la Universitat Autònoma $^{56}$. La transcendència d'aquest Centre ultrapassà la seva trajectòria i va esdevenir decisiu a les escoles catalanes de formació de mestres, les que ja existien i les que s'establiren de nou ${ }^{57}$

53 Ferdinand Oury i A.V., tenien com a eix fonamental la psicoteràpia experimental, utilitzaven les tècniques Freinet, tenien orientació freudiana i criticaven la no-directivitat. Michel Lobrot i G.L és basaven en la psicopedagogia, criticaven la directivitat i fomentaven l'autogestió; valoraven prioritàriament la teoria de Rogers i qüestionaven la psicoanàlisi.

54 Tots aquests plantejaments, a nivell pràctic i teòric els va experimentar en les institucions següents :Els minyons escoltes i guies de Sant Jordi. El Servei de Colònies de Vacances: les escoles Esplai, Costa i Llobera, Escola de Mestres de Sant Cugat, Escola de Mestres de Girona, Escola d'Educadors en el Lleure: ajuntaments de Barcelona i Girona (Tota la informació està extreta de; Franch 1973 i 1975 i dades comprovables d'Internet) 55 .En aquest sentit, no hem d'oblidar un grup de mestres de Girona, que des dels anys setanta, van treballar, des de dins de l'escola pública, a favor d'una reforma escolar.

56 Sobre la dita trajectòria, vegeu:: Maria Villanueva i Margalef, (1973)

57 El seu moment àlgid l'hem de situar a finals dels setanta i principis dels vuitanta. Es va caracteritzar per la gestió democràtica, una estructura participativa, el principi d'igualtat de sou i de treball per a tot el personal docent. El seu objectiu era formar mestres que treballessin per a la integració de l'alumne a la realitat social y lingüística del país. El català era la llengua vehicular i el propòsit era que els mestres acabessin els seus estudis 
Fins aquí hem fet una descripció del més destacat del moviment pedagògic renovador. Intentem, tot seguit oferir un tast dels veritables objectius, més o menys assolits, com una mena de resum de la seva trajectòria.

\section{Reflexions i final d'un període.}

Dels estudis de l'evolució de les diferents activitats de "Rosa Sensat dels treballs que han aparegut sobre diverses escoles vinculades al moviment d'escoles actives i de la meva experiència personal es pot afirmar que hom partia de la concepció de l'educació integral. No s'havia de pensar en l'alumne sinó en la formació d'una persona concreta. Hom s'oposava radicalment a la rigidesa ideològica, a l'autoritarisme, i a la cotilla pedagògica del model franquista.

L'escola no es concebia com una suma de personal docent i no docent sinó com un col.lectiu. A l'esmentat moviment, hom preveia la introducció gradual i progressiva de la llengua catalana per assolir la catalanització completa en llengua i continguts, tot i que, en cap moment, es va considerar el català com a llengua nacional. Es manifestà, també, un interès especial per l'educació mixta o coeducació. Es mostrava afinitat amb els principis de l'escola activa i l'aplicació dels seus mètodes amb llurs variants i adaptacions. Hom considerava principis fonamentals l'ensenyament individualitzat $i$ el cooperatiu, amb el consegüent treball en equip i la gestió democràtica de l'escola.

Dins dels conceptes d'interdisciplinarietat o globalització, el moviment s'obria a noves àrees de coneixement, com és ara les Ciències Socials i l'Educació Sexual, a més de les ja citades. Es posava, a més, especial èmfasi en la sociabilitat i en les expressions musical i artística. Altrament hom reivindicava la psicologia escolar i la figura del psicòleg, com a eines per millorar el coneixement i el seguiment evolutiu de l'infant.

Era prioritària, també, la participació activa dels pares i mares. Hi era present, a més, un interès envers la formació permanent dels mestres, que es podia realitzar en l'estructura educativa de "Rosa Sensat" i, des de finals dels setanta, a les noves escoles de formació del professorat.

A més, de les limitacions imposades pel context sociopolític, hi havia problemes interns que la Institució i el moviment ja van preveure. Intentarem però, valorar, des de la nostra perspectiva, algunes de les limitacions internes. Marta Mata va manifestar a finals dels anys seixanta els problemes de les Escoles d'Estiu, que es resumeixen en els punts següents:

"Les contradiccions entre els mòbils i els objectius de la Institució i la societat real.. El problema de l'augment de la massificació. La qualitat dels cursos, difícil de controlar en una situació de demanda creixent. El problemes derivats d'una major obertura

dominant el català i el castellà. Els alumnes feien pràctiques en una escola, que estigués d'acord amb llurs postulats, sempre que això fos possible 
social, perquè començava a conviure a les Escoles d'Estiu, gent d'ideologies molt diverses" 58 .

Tot i les previsions, aquests perills no s'acabaren de superar. Potser el més problemàtic fou que el moviment va mirar excessivament cap a una sola direcció; resumint, no s'acabà de superar el maniqueisme. Aquest fet es manifestà també en l'oposició política i, en part, encara s'arrossega.

Heus aquí, doncs, a gran trets i de forma molt esquemàtica, el que va representar pel món educatiu català, en particular, i per alguns sectors d'aquest món a la resta de l'Estat el moviment pedagògic renovador, encapçalat, en bona part, per "Rosa Sensat". Els canvis polítics de finals dels setanta i principis dels vuitanta ens situen en una nova etapa, en la qual el moviment que hem estudiat deixa de ser protagonista.

El nou marc politicoeducatiu tindrà una gran influència sobre la nova realitat escolar. Les seves contradiccions, els seus encerts i els seus fracassos pertanyen a una altra història.

\section{Bibliografia Citada}

ALSINA, Àngel; SOLER, Joan (coord.) (2005). Ma Antònia Canals. El compromís amb la renovació de l'escola . Vic: Eumo. Universitat de Vic.

Alumnes de l'escola de Barbiana; MILANI, Lorenzo. (1998). Carta a una mestra. Pròleg de Miquel Martí i Solé. Vic: Eumo, 122 pàg. ( primera edició catalana, anterior a la castellana és de 1969),.

BAUDELOT, Christian ; ESTABLET, Roger. (1971). L'École capitaliste en France. París : François Maspero, 347 pàg.

BOSCH, Josep Mํ. (1963)." ''école Decroly de Barcelone". Education ; (Bruxelles), núm. 84.

BOSCH, Josep Mํ. (1974). “La escuela Decroly de Barcelona”. Bordón (Madrid), núm. 201.

BOSCH, Josep Mạ., MUSEt, Margarida. (1980). Iniciació al mètode Decroly. Una aplicació a Barcelona. Barcelona: Teide, 184 pàg.

CANALS, Ma Antònia; Codina, M. Teresa; Cots, Jordi; Darder, Pere; Mata, Marta; Roig, Anna Ma (2001). La renovació pedagògica a Catalunya des de dins (1940-1980). Fets i records, Barcelona: Edicions 62, 265 pàg.

CODINA i MIR, Mํㅡㄹ Teresa. (2002). "Rosa Sensat y los orígenes de los Movimientos de Renovación Pedagógica". Historia de la Educación. Revista Interuniversitaria, núm., 21

CODINA, Mํㅡㄹ Teresa, ( 2007), Educar en temps difícils. Escola Talitha, 1956-1974, Pròleg de Bru Rovira Jarque. Vic: Eumo editorial, 445 pàg.

FRANCH, Joaquim 1973 i 1975). "Vers un nou medi educatiu. El mestre en el grup classe "Quaderns d’Educació, núm. 1 i 7.

58 . Citat a Jordi Monés Pujol-Busquets (1981), pàg.56. 
FREIRE, Paolo, ILLICH, Iván. (1975) "Conversando con Paolo Freire”. Cuadernos de Pedagogía, juliol-agost, núm. 7-8.

FREIRE, Paolo. " Discurs íntegre del doctorand a la Universitat de Barcelona". Temps d'Educació,, núm. 1,1 de setembre.

GALI, Jordi. (1978). "Panorama històric de l'Escola Catalana. L'engegada de postguerra" Butlletí Interior dels Seminaris de la Dec. Òmnium Cultural. Especial Escola Catalana., núm. 130, 131, 132 , maig, juny, juliol .

GONZÀLEZ-AGÀPITO, Josep, 1989. Rosa Sensat i Vilà. Fer de la vida escola. Pròlegs d'Angeleta Ferrer i Marta Mata. Barcelona: Rosa Sensat-Edicions 62, 156 pàg.

MATA, Marta. (1999) Doctora honoris causa. Discurs llegit a la cerimònia d'investidura celebrada a la sala d'actes del Rectorat el dia 5 de maig de l'any 1999. Bellaterra: Universitat Autònoma de Barcelona, 57 p. [Presentació de Marta Mata per Pilar Benejam i Arguimbau, pàg., 5-11].

MATA, Marta (2001). "Un període difícil”: CAnALs, Ma Antònia/et al.

MONÉS i PUJOL-BUSQUETS, Jordi (1981). Els primers quinze anys de Rosa Sensat. Pròleg de Marta Mata. Barcelona: Rosa Sensat/Edicions 62, 293 pàg.

MONÉS i PUJOL-BUSQUETS, Jordi (2011), La pedagogia catalana al segle XX. Els seus referents. Presentació de Josep Gonzàlez-Agàpito. Barcelona:Pagès editors/Institut d'Estudis Catalans, 544 pàg.

PORTELL, Raimon (2007). Marta Mata. El camí de l'escola. Barcelona:Generalitat de Catalunya. Diputació de Barcelona. Ajuntament de Barcelona, 156 pàg.

REICH, Wilhem (1970). La Revolución sexual. Por una estructura de carácter autónomo del hombre. París, Ruedo lbérico, 254 p. (l'original alemany és del 1936).

SILVA, Alberto/et al.(1975)“ Dossier Freire//llich”,Cuadernos de Pedagogía, juliol-agost, núm., 7-8; Cuadernos de Pedagogía, (1977), maig, núm., 29. (1978), abril, núm. 40.

SUCHODOLSKY, Bogdan. (1974). Fundamentos de pedagogía socialista. Barcelona: Laia, 285 pàg.

VILLANUEVA I MARGALEF, Maria (1973). 1973-1983. Deu anys de formació de mestres. Barcelona: Escola de mestres de Sant Cugat. Universitat Autònoma de Barcelona, 59 